\title{
Unequal access to timely physiotherapy for children with cerebral palsy in one Swedish county: a retrospective chart review
}

\author{
Linnéa Hekne ${ }^{1}$, Cecilia Montgomery ${ }^{2}$, and Kine Johansen ${ }^{2}$ \\ ${ }^{1}$ Västerås Central Hospital \\ ${ }^{2}$ Uppsala University
}

June 15, 2020

\begin{abstract}
Rational and aims: Early intervention is considered best practice for children with Cerebral Palsy (CP). Given that access to such intervention is known to vary, we aimed to investigate whether children with CP in Uppsala County, Sweden, have equal access to timely physiotherapy. Furthermore, we describe their birth history and CP profile to learn more about typical features that might enable earlier identification. Method: We conducted a retrospective chart review study including children born in the county from 2010 to 2016, who received a CP diagnosis by December 2018. Entries by doctors and physiotherapists working at Uppsala University Children's Hospital were reviewed. Results: Thirty-eight children were included (21 girls). Twenty-two $(58 \%)$ were term born. Age at first visit to physiotherapy varied greatly and depended on referral source $(\mathrm{p}<0.000)$ and number of risk factors for $\mathrm{CP}(\mathrm{p}<0.000)$. Children considered at low risk for CP received therapy later. Severity of motor impairment $(\mathrm{p}=0.001)$ and number of risk factors $(\mathrm{p}=0.014)$ influenced age at referral to habilitation services. Twenty-eight $(74 \%)$ children were ambulatory at 2 years of age. Unilateral $(n=16)$ and bilateral $(n=17)$ spastic CP was most common. Children referred from the child health services (CHS) had milder forms of CP. Conclusion: Children with CP have unequal access to timely physiotherapy, and children referred from the CHS have the most delayed access. All professionals performing developmental surveillance and health monitoring should receive proper training and use evidence-based assessment methods when available to provide safe and equal care. Physiotherapy should be available prior to formal medical diagnosis.
\end{abstract}

\section{INTRODUCTION}

Cerebral Palsy $(\mathrm{CP})$ is a clinical diagnosis used to describe a spectrum of movement disorders caused by non-progressive lesion/abnormalities that occurred in the developing brain. ${ }^{1,2}$ Although the incidence is declining due to improvements in care, ${ }^{2,3} \mathrm{CP}$ is still considered the most common physical disability in childhood, affecting 1.4 per 1000 in high-income countries. ${ }^{3}$ Increasing evidence points to the importance of early intervention for motor disorders in children. ${ }^{3-7}$ To take full advantage of the plasticity of the developing brain it should begin during the first months of life. ${ }^{3,4,6,7}$

Several systems are in place to identify children with developmental disabilities. The Swedish Child Health Services (CHS), a free-of-charge primary healthcare service for children aged 0-5 years, ${ }^{8}$ offers a comprehensive well-child surveillance program including twelve scheduled visits during the child's first year of life. Children born prematurely (gestational age $<28$ weeks) or with other neonatal morbidities are also enrolled in neonatal follow-up programs guided by national guidelines and adjusted to local routines. ${ }^{9}$ In the current organizations, the early detection tools used are different. Within routine CHS practice, motor development is assessed using milestone achievement, ${ }^{8}$ while neonatal follow-up use evidence-based assessment methods.

Children with a complicated birth history are considered at risk for developmental disabilities and are routinely enrolled in neonatal follow-up. ${ }^{5,7}$ However, these high-risk infants only constitutes half of all children with $\mathrm{CP} .{ }^{5,10-13}$ Studies have shown that children considered at low risk for $\mathrm{CP}$ have delayed access 
to intervention, ${ }^{11-13}$ and have revealed that the Swedish CHS only makes minor contributions to early detection of $\mathrm{CP}$ and severe health problems ${ }^{14,15}$ Hence, children considered at low risk for CP are deprived interventions that are known to improve outcomes. ${ }^{3,6,10}$ This is contrary not only to the Health Care Act (HSL 2017:30), which aims to achieve good health and equal care for the entire population, but also the Convention on the Rights of the Child (SFS 2018:1197). The latter became Swedish law in January 2020 and states that children shall have access to the highest attainable standard of health and that no child should be deprived access to healthcare or rehabilitation services.

As physiotherapy is essential in promoting motor development and preventing secondary consequences, we investigated whether children with $\mathrm{CP}$ have equal access to timely physiotherapy. Furthermore, we describe their birth history and CP profile to learn more about typical features that might enable earlier identification.

\section{METHODS}

This retrospective chart review included children born in Uppsala County from 2010 to 2016 who had received a CP diagnosis by December 2018. The children were identified through the local CP register $(\mathrm{n}=38)$, which is part of the Swedish National Cerebral Palsy Surveillance Program and Registry (CPUP) ${ }^{16}$ and through the electronic medical chart system $(n=19)$. Children who were born outside Uppsala County or had moved into the county after 1 year of age were excluded from the study $(n=18)$, leaving 39 eligible children.

Uppsala County have approximately 295,000 inhabitants living in either urban Uppsala or its surrounding rural areas. During the study period, 28,665 children were born in the county (Statistics Sweden), distributed as following: 668 born before gestational week 31 (2.3\%), 1447 between gestational weeks 32-36 (5.1\%) and 26,550 born at term $(92.6 \%)$. These children attended well-child visits at any of the 44 child health centers in the county. Children enrolled in the neonatal follow-up program (gestational age $<32$ weeks) attended visits at Uppsala University Children's Hospital, where the physiotherapist routinely assessed the infants' motor performance using Structured Observation of Motor Performance in Infants (SOMP-I) at 2, 4 and 10 months corrected age. ${ }^{17}$ When a diagnosis of $\mathrm{CP}$ was made by the neuropediatrician, the child was referred to habilitation services. The final diagnosis of CP is routinely made around four years of age. ${ }^{16}$

\section{Data collection}

The data collection was performed during the summer of 2018, with a complementary search during the summer of 2019. The latter search revealed two additional children meeting the inclusion criteria, both born in the fall of 2016. The entries by doctors and physiotherapists working at the children's hospital were reviewed using a predefined template (Appendix 1). All data related to age were corrected for prematurity if appropriate (gestational age $<37$ weeks). The first author performed most of the data collection, while the last author complemented it when needed. Any uncertainties were discussed until consensus was reached.

\section{Measures}

Referral source was defined as the professional that referred the child to physiotherapy. Complicated birth history was defined as the number of known risk factors for CP, such as stroke, infections, or seizures (Appendix 1), detectable before 5 months of age. Motor severity was described using the Gross Motor Function Classification System (GMFCS) at two years. ${ }^{18}$ Distinctions between levels are based on functional abilities, where Level I indicates the highest and Level V the lowest functional level. Children at GMFCS Level I-III are ambulatory with or without assistant, while those at GMFCS Level IV-V are considered nonambulatory and dependent on wheeled mobility. Type of $C P$ was described by motor type and topography.

\section{Statistical analysis}

Descriptive statistics were applied to characterize our sample and are presented in the text and tables. Kruskal-Wallis H Test was conducted to examine the differences between referral source, risk factors, GMFCS level and type of CP (ordinal/categorical data) regarding the first visit to physiotherapy and age at referral to habilitation services (continuous data). A significance level of $\mathrm{p}<0.05$ was applied, and significant values 
were adjusted using Bonferroni correction for multiple tests. All calculations were performed using IBM SPSS Statistics 24 for Windows (SPSS Inc., Chicago, IL, USA).

\section{Ethical approval}

Due to the retrospective nature of the study and the risk of losing participants in a small sample, we received approval by the Regional Ethical Review Board in Uppsala, Sweden (reg. no. 2018/173) as well as the Heads of Operations at Uppsala University Children's Hospital and the Habilitation Services in Uppsala to review data without obtaining informed consent. All data are presented on group level to prevent individual child or caregiver identification.

\section{RESULTS}

Thirty-nine children (21 girls) met the inclusion criteria (Table 1), giving a prevalence of CP in Uppsala County of 1.4 cases per 1000 or an incidence of 5.4 cases per year. One child, who was missed early and not considered representative for the sample, was excluded from the statistical analysis.

Two-thirds of the children were born at term $(\mathrm{n}=22)$ (Table 1$)$, and the mean gestational age was 35 weeks (min-max 23-41). The neonatologist was the primary referral source $(\mathrm{n}=22)$, while the remaining children were referred from the neuropediatrician $(n=7)$ or the CHS $(n=9)$. Of the 22 infants referred from the neonatologist, 17 were girls.

\section{Access to physiotherapy}

Access to early physiotherapy was dependent on referral source $(p<0.000)$ and number of risk factors $(p<$ 0.000) (Table 2). There was no significant difference in age at first visit regarding motor severity or type of CP. Infants referred from the neonatologist had significantly earlier access to physiotherapy than infants referred from the neuropediatrician $(p=0.021)$ and the CHS $(p<0.000)$ (Table 1/Fig. 1). On average, infants referred from the neonatologist were 6 weeks old at first visit to physiotherapy (Table 1), while the corresponding age for infants referred from the neuropediatrician and the CHS was approximately 6 and 11 months, respectively.

Infants with [?]3 known risk factors for CP had significantly earlier access to physiotherapy than children with no known risk factors $(p<0.000)$ or those with one or two $(p=0.011)$ (Table 2/Fig. 1). On average, infants with [?]3 known risk factors were less than 6 weeks of age at first visit to physiotherapy (Table 1), while the corresponding age for infants with no known risk factors and those with one or two was approximately 11 and 5 months, respectively.

The severity of motor impairment ( $p=0.001)$ and the number of known risk factors $(p=0.014)$ influenced age at referral to the habilitation services (Table 2/Fig. 1). Children at GMFCS Level IV and V were referred at a significantly younger age than children at GMFCS Level I ( $p=0.004$ and $p=0.015$, respectively), and children with [?]3 known risk factors were referred significantly earlier than children with no known risk factors $(p=0.037)$. Referral source and type of CP did not influence age at referral to the habilitation services.

\section{Description of the population regarding birth history and CP profile}

A complicated birth history was more common among the infants referred from the neonatologist (mean: 5.6 risk factors) compared to those referred from the neuropediatrician (mean: 1.6) and the CHS (mean: 0.3) (Table 1). Regardless of medical history, most children had a high functional level at 2 years of age, where $28(73.7 \%)$ were ambulatory with or without assistant (Table 1). Across groups, 15 children (39.5\%) were classified at GMFCS Level I (Table 1). The children classified as non-ambulatory according to GMFCS $(\mathrm{n}=10)$ were evenly distributed from gestational week 28 to term (Table 3$)$, all of which had [?]1 known risk factors for $\mathrm{CP}$ and $70 \%$ had [?]3 (Table 1). However, children with [?]3 risk factors were distributed across all GMFCS levels (Table 3). Of the infants referred from the CHS, all, except one, had a functional Level I or II according to GMFCS $(n=8)$ (Table 1$)$. The most common types of CP were unilateral $(n=16)$ and bilateral $(\mathrm{n}=17)$ spastic CP (Table 1$)$. 


\section{DISCUSSION}

Our study show that there are great variability in age at first visit to physiotherapy. The prevalence of CP was similar to figures reported in other high-income countries, ${ }^{3}$ and infants born at term constituted $58 \%$ of all CP cases.

Similar to Boychuck and colleagues, ${ }^{12}$ referral source and complicated birth history predicted earlier access to physiotherapy. It is important to acknowledge that children with a complicated birth history are considered high risk for $\mathrm{CP}$ and are routinely enrolled in neonatal follow-up. ${ }^{7}$ In this setting, professionals know they are assessing children at risk for CP. The children may also have more severe impairments, which may partly explain the finding of earlier detection. ${ }^{12}$

However, only slightly more than half of all children with CP are enrolled in neonatal follow-up. ${ }^{5,10-13}$ For the remaining children age at referral varies considerably, ${ }^{11-13}$ where the primary healthcare services including the CHS have the greatest delays. ${ }^{11-14}$ Although the CHS is striving to improve their methods and the infants in our study were identified at an earlier age than previous studies, ${ }^{11-14}$ the children are nevertheless referred later than high-risk infants and with greater variability. In our study, children referred from CHS had few, if any, known risk factors for $\mathrm{CP}$ and less severe motor impairments, which may be challenging to detect. ${ }^{10,13,19}$

Previous research has shown that children with mild motor impairments and unilateral and bilateral spastic CP have delayed access to early intervention. ${ }^{13,20}$ While this was not confirmed in our study, motor impairment severity and complicated birth history affected age at referral to habilitation services. As a formal medical diagnosis is required for referral to habilitation services, our results may imply that having a known medical history and more severe motor problems makes diagnosing CP easier.

To meet the requirements of the Health Care Act and the Convention on the Rights of the Child, evidencebased assessment methods should be an integrated part of developmental surveillance and health monitoring. Standardizing care could potentially reduce variability across organizations and professionals, ${ }^{21}$ hence increasing equality and patient safety. Furthermore, using such methods improves accuracy, enables earlier identification (including mild delays or suspected deviations) and provides more information compared to clinical judgement alone..$^{7,10,19,22}$ Not using such methods will delay detection of children with $\mathrm{CP},{ }^{11-13}$ consequently depriving children of interventions known to be beneficial. ${ }^{3,4,6,7}$ The fact that the rate of $\mathrm{CP}$ is falling and that $\mathrm{CP}$ severity is lessening further highlight this need. ${ }^{3}$ In our study, the majority of the children had a high functional level, and of those referred from the CHS, all but one had mild motor impairment. A recent scoping review suggested that feasible methods for well-child surveillance are lacking, ${ }^{23}$ we have shown, however, that when child health nurses used SOMP-I in routine well-child surveillance it appeared to be clinically useful. ${ }^{24}$

Thus, all professionals performing developmental surveillance and health monitoring should receive adequate training, use evidence-based assessment methods when available and be skilled in discriminating atypical movement from variations in typical movement. ${ }^{7}$ However, it is important to remember that proper assessment of infants using any standardized method is an acquired skill requiring practice over time. Nurses learning to use the SOMP-I stressed that becoming a proficient assessor requires training and practice. ${ }^{25}$ Furthermore, infants displaying aberrant motor performance should have access to physiotherapy prior to any formal medical diagnosis, as mild cases with an uncomplicated birth history can be particularly difficult to diagnose. ${ }^{10}$

Only four children were born before gestational week 28, while $75 \%$ had [?]1 known risk factors for CP. As one stated aim of the guidelines for neonatal follow-up is to detect $\mathrm{CP},{ }^{9}$ all children with known risk factors should be included in the follow-up. ${ }^{7}$ Furthermore, to enable timely intervention, it should be clearly stated in the guidelines that infants' motor performance should be assessed using an evidence-based assessment method within the first months of life corrected age.

\section{Limitations}


Our results are based on a small clinical population from one Swedish county. Nevertheless, the prevalence of $\mathrm{CP}$ was similar to figures reported elsewhere, indicating that it is a representative sample. The youngest children were only 2 years of age when we conducted the initial search, which entails the risk that not all children with CP were identified. However, no child was identified after two years, and only two children meeting the inclusion criteria were identified in the complementary search. The retrospective design limited our access to the entries made at the children's hospital, possibly resulting in missed information from other sources, such as the CHS. The review was mainly performed by the first author, and to reduce the risk of bias, a template was used when collecting the data.

\section{CLINICAL IMPLICATIONS}

Early identification and timely intervention are widely accepted as best practice for children with CP. Infants in Uppsala County have unequal access to timely physiotherapy, where children considered at low risk for $\mathrm{CP}$ receive therapy later. The high variability in referral practices suggests that knowledge of $\mathrm{CP}$ attributes in young children varies widely across organizations and professionals. It is especially children referred from the CHS who have delayed access to intervention, indicating that the current practice of measuring milestone achievement does not efficiently detect CP. This is concerning given the CHS's vital role in early detection of developmental disabilities.

To provide high quality care that is equal and safe, all professionals working with developmental surveillance and health monitoring, regardless of organizational level, need appropriate knowledge of typical and atypical motor development, including early clinical signs of CP. Without continuous professional development initiatives to increase such knowledge, children will continue to experience delayed access to intervention. Evidence-based assessment methods should be used when available, as these improve early detection and support clinical decision-making. Furthermore, when aberrant motor performance is observed, the child should promptly be referred to physiotherapy regardless of formal medical diagnosis.

\section{ACKNOWLEDGEMENTS}

We wish to thank Kristina Persson (Associate Professor and physiotherapist) for valuable feedback during preparation of the manuscript, as well as to acknowledge the collaboration provided by the Habilitation Services in Uppsala County, Sweden.

Uppsala University and Uppsala County Council Grants for Healthcare Research and Uppsala University through the Hedström Foundation and the Larsson Foundation funded this study. The funders had no role in study design, data collection and analysis, decision to publish, or preparation of the manuscript.

\section{COMPETING INTERESTS}

SOMP-I is owned by Barnens rörelsebyrå ekonomisk förening (economic association) Uppsala, Sweden. Kine Johansen is a partner of Barnens rörelsebyrå. All other authors have no conflicts of interest to disclose.

\section{REFERENCES}

1. Rosenbaum P, Paneth N, Leviton A, et al. A report: the definition and classification of cerebral palsy April 2006. Dev Med Child Neurol 2007;49:8-14.

2. te Velde A, Morgan C, Novak I, et al. Early Diagnosis and Classification of Cerebral Palsy: An Historical Perspective and Barriers to an Early Diagnosis. J Clin Med 2019;8:1599.

3. Novak I, Morgan C, Fahey M, et al. State of the Evidence Traffic Lights 2019: Systematic Review of Interventions for Preventing and Treating Children with Cerebral Palsy. Curr Neurol Neurosci Rep 2020;20:3.

4. Johnston MV. Plasticity in the developing brain: Implications for rehabilitation. Dev Disabil Res Revs 2009;15:94-101.

5. McIntyre S, Morgan C, Walker K, et al. Cerebral Palsy—Don't Delay. Dev Disabil Res Rev 2011;17:114129 . 
6. Morgan C, Darrah J, Gordon AM, et al. Effectiveness of motor interventions in infants with cerebral palsy: a systematic review. Dev Med Child Neurol 2016;58:900-909.

7. Novak I, Morgan C, Adde L, et al. Early, Accurate Diagnosis and Early Intervention in Cerebral Palsy: Advances in Diagnosis and Treatment. JAMA Pediatr 2017;171:897-907.

8. Tell J. Swedish Child health services. Rikshandboken i Barnhälsovård [cited 2020 May 15]. Available from: https://www.rikshandboken-bhv.se/metoder-riktlinjer/informationsmaterial/swedish-child-health-services/

9. Svenska Neonatalföreningen. Nationella riktlinjer för uppföljning av neonatala riskbarn [cited 2020 May 20]. Available from: https://neo.barnlakarforeningen.se/wp-content/uploads/sites/14/2014/03/NationellaUppfoljningsprogrammet-2015.pdf

10. Morgan C, Fahey M, Roy B, et al. Diagnosing cerebral palsy in full-term infants. J Paediatr Child Health 2018;54:1159-1164.

11. Hubermann L, Boychuck Z, Shevell M, et al. Age at Referral of Children for Initial Diagnosis of Cerebral Palsy and Rehabilitation Current Practices. J Child Neurol 2016;31:364-369.

12. Boychuck Z, Bussières A, Goldschleger J, et al. Age at referral for diagnosis and rehabilitation services for cerebral palsy: a scoping review. Dev Med Child Neurol. 2019;61:908-914.

13. Boychuck Z, Andersen J, Fehlings D, et al. Current Referral Practices for Diagnosis and Intervention for Children with Cerebral Palsy: A National Environmental Scan. J Pediatr 2020;216:173-180.e1.

14. Lindström K, Bremberg S. The contribution of developmental surveillance to early detection of cerebral palsy. Acta Paediatr 1997;86:736-739.

15. Magnusson M, Persson K, Sundelin C. The effectiveness of routine health examinations at 2, 6, 9 and 12 months of age: experiences based on data from a Swedish county. Child Care Health Dev 2001;27:117-131.

16. Alriksson-Schmidt AI, Arner M, Westbom L, et al. A combined surveillance program and quality register improves management of childhood disability. Disabil Rehabil 2017;39:830-836.

17. Montgomery C, Johansen K, Lucas S, et al. The Structured Observation of Motor Performance in Infants can detect cerebral palsy early in neonatal intensive care recipients. Early Hum Dev 2017;113:31-39.

18. Palisano R, Rosenbaum P, Walter S, et al. Development and reliability of a system to classify gross motor function in children with cerebral palsy. Dev Med Child Neurol 1997;39:214-223.

19. Hix-Small H, Marks K, Squires J, et al. Impact of implementing developmental screening at 12 and 24 months in a pediatric practice. Pediatrics 2007;120:381-389.

20. Granild-Jensen JB, Rackauskaite G, Flachs EM, et al. Predictors for early diagnosis of cerebral palsy from national registry data. Dev Med Child Neurol 2015;57:931-935.

21. Institute of Medicine (US) Committee on Quality of Health Care in America. Creating Safety Systems in Health Care Organizations. In: Kohn LT, Corrigan JM, Donaldson MS, eds. To Err is Human: Building a Safer Health System. Washington (DC): National Academies Press; 2000. 155-201 pp.

22. King TM, Glascoe FP. Developmental surveillance of infants and young children in pediatric primary care. Curr Opin Pediatr 2003;15:624-9.

23. Garfinkle J, Li P, Boychuck Z, et al. Early clinical features of Cerebral Palsy in children without perinatal risk factors: A Scoping Review. Pediatr Neurol 2020;102:56-61.

24. Johansen K, Persson K, Sonnander K, et al. Clinical utility of the Structured Observation of Motor Performance in Infants within the child health services. PLOS ONE 2017;12:e0181398. 
25. Johansen K, Lucas S, Bokström P, et al. 'Now I use words like asymmetry and unstable': nurses' experiences in using a standardized assessment for motor performance within routine child health care. J Eval Clin Pract 2016;22:227-234.

\section{Hosted file}

Table 1 Unequal access to timely physiotherapy for children with cerebral palsy in one Swedish county.d available at https://authorea.com/users/333616/articles/459765-unequal-access-to-timelyphysiotherapy-for-children-with-cerebral-palsy-in-one-swedish-county-a-retrospectivechart-review

\section{Hosted file}

Table 2 Unequal access to timely physiotherapy for children with cerebral palsy in one Swedish county.d available at https://authorea.com/users/333616/articles/459765-unequal-access-to-timelyphysiotherapy-for-children-with-cerebral-palsy-in-one-swedish-county-a-retrospectivechart-review

\section{Hosted file}

Table 3 Unequal access to timely physiotherapy for children with cerebral palsy in one Swedish county.d available at https://authorea.com/users/333616/articles/459765-unequal-access-to-timelyphysiotherapy-for-children-with-cerebral-palsy-in-one-swedish-county-a-retrospectivechart-review

\section{Hosted file}

Figure 1 Unequal access to timely physiotherapy for children with cerebral palsy in one Swedish county. available at https://authorea.com/users/333616/articles/459765-unequal-access-to-timelyphysiotherapy-for-children-with-cerebral-palsy-in-one-swedish-county-a-retrospectivechart-review 